Karadeniz Uluslararası Bilimsel Dergi

Volume: 52, Winter-2021, p. (152-163)

ISSN: 1308-6200 DOI Number: https://doi.org/10.17498/kdeniz.1015403

Research Article

Received: Oct 27, 2021 | Accepted: Nov 16, 2021

This article has been checked for plagiarism.

\title{
HARRAN OVASI ARKEOLOJİK YÜZEY ARAŞTIRMASI 2020 YILI ÇALIŞMALARININ ÖN DEĞERLENDİRMESI
}

\section{PRELIMINARY ASSESSMENT ON THE ARCHAEOLOGICAL SURVEY OF THE HARRAN PLAIN IN 2020}

\section{ПРЕДВАРИТЕЛЬНАЯ ОЦЕНКА АРХЕОЛОГИЧЕСКИХ ИССЛЕДОВАНИЙ ПОВЕРХНОСТИ ХАРРАНСКОЙ РАВНИНЫ В 2020 ГОДУ}

\author{
Mehmet ÖNAL* \\ Süheyla İrem MUTLU** \\ Semih MUTLU ${ }^{* * *}$
}

\section{ÖZ}

Eski çağlardan itibaren önemli bir konumda olan ve Mezopotamya'ya açılan bir kapı durumundaki Harran Ovası, Anadolu platosu ile güneydeki düzlükler arasındaki ilişkiyi sağlayan, Mezopotamya kültürleri ile çağlar boyu iç içe yaşamıştır ve Önasya Kültür tarihi açısından da büyük önem taşımaktadır. Makalemizin başlığı olan Harran Ovası Yüzey Araştırması 2020 çalışmalarında öncelikli olarak Harran Ören Yeri merkez alınarak ilçenin Sur içi ve Sur dışında gerçekleştirilen çalışmalar ele alınmıştır. Daha sonra Harran Ören Yeri'nin $15 \mathrm{~km}$ kuzey ve kuzeybatısına kadar saptanan yerleşimlerin boyutları, her yerleşimde tespit edilen dönemler buluntulara göre değerlendirilmiştir. Ayrıca söz konusu yerleşimlerin birbirleriyle ve de Harran kentiyle olan ilişkileri anlaşılmaya çalışılmış̧ır. Bu bağlamda Balih Nehri'nin kuzey hattı boyunca saptanan yerleşimlerin konumları, büyüklükleri, yayılımları saptanmıştır. Ayrıca her bir yerleşimden toplanan arkeolojik buluntular vasıtasıyla tüm teknik ve istatistiksel veriler kullanılarak bölgedeki yerleşimlerin yayılım alanları, bu yerleşimlerin birbirleriyle bağlantılarının saptanması, yerleşim şablonlarının çıkarılması, bölgenin her dönemde kültürel yapısının belirlenmesi, merkez ve merkeze bağlı yerleşimler ile aşağı şehirlerin tespitine yönelik çalışmalarla bölgeyle çevre kültürler arasındaki ilişkiler ortaya konulmaya çalışılmıştır. Bu çerçevede Harran Ören Yeri merkez alınarak Harran Ulu

\footnotetext{
* ORCID: 0000-0002-5182-4443, Prof. Dr., Harran Üniversitesi Fen Edebiyat Fakültesi, Arkeoloji Bölümü, 63300-ŞANLIURFA. monalbz@yahoo.com

** ORCID: 0000-0001-7935-2890, Arş. Gör., Harran Üniversitesi Fen Edebiyat Fakültesi, Arkeoloji Bölümü, 63300-ŞANLIURFA. suirem@gmail.com

*** ORCID: 0000-0003-2920-6275, Öğr. Gör., Harran Üniversitesi Fen Edebiyat Fakültesi, Arkeoloji Bölümü, 63300-ŞANLIURFA. semihmutlu@ @harran.edu.tr
} 


\section{Harran Ovası Arkeolojik Yüzey Araştırması 2020 Yılı Çalışmalarının...}

Camii'nin kuzeyi, kuzeybatısı, doğusu, Harran Höyük'ün güneybatı, güneydoğu, doğu ve batı yamaçları, ayrıca dış surun etrafı ve yakınındaki tarlalar ve Harran Ören Yeri merkez alınarak kuzey, kuzeybatı ve kuzeydoğu boyunca ilerlenerek gezilen yerleşimlerde saptanan dönemler ve buluntular değerlendirilmiştir.

Anahtar Kelimeler: Harran Ören Yeri, Harran Ovası, Yüzey Araştırması, Yerleşim Şablonu, Kültürler

\section{ABSTRACT}

Harran Plain, which has been in an important position since ancient times and is a gateway to Mesopotamia, has lived together with Mesopotamian cultures for ages, providing the relationship between the Anatolian plateau and the plains in the south, and is of great importance in terms of the history of the Near East. In the researches of the Harran Plain Survey 2020, which is the title of our article, the studies carried out in and outside of the Ancient Harran City Wall, primarily by taking the Harran Archaeological Site as the center, were discussed. Then, the dimensions of the settlements found up to $15 \mathrm{~km}$ north and northwest of the Ancient Harran City and the periods found in each settlement were evaluated according to the finds. In addition, the relations of these settlements with each other and with the city of Harran were tried to be understood. In this context, the locations, sizes and spreads of the settlements found along the northern line of the Balih River were determined. In addition, by using all the technical and statistical data collected from each settlement, the distribution areas of the settlements in the region, the connections of these settlements with each other, the determination of the settlement patterns, the determination of the cultural structure of the region in every period, the determination of the center and the settlements connected to the center and the lower cities, and the surrounding cultures with the region. relations between them have been tried to be revealed. In this framework, taking the Harran City as the center, the north, northwest, east of the Harran Great Mosque, the southwest, southeast, east and west slopes of the Harran Höyük, as well as the fields around and near the outer wall, and the Harran City are centered on the north, northwest and northeast. The periods and finds found in the settlements visited were evaluated.

Key Words: Harran City, Harran Plain, Archaeological Survey, Settlement Models, Cultures

\section{АННОТАЦИЯ}

Харранская равнина, занимающая важное положение с древних времён и являющая воротами в Месопотамию, веками был переплетён с месопотамскими культурами, обеспечивая связь между анатолийским плато и равнинами на юге. Она имеет большое значение с точки зрения истории культуры Ближнего Востока. В нижеследующей статье исследуются раскопки руин внутри и около крепости в центре Харрана. На основе археологоческих материалов было установлено площадь поселений, найденных на расстоянии в 15 км. к северу и северо-западу от руин Харрана и археологические периоды каждого поселения. Кроме этого, попытались изучить отношения этих поселений между собой и с городом Харран. В этом контексте были определены местонахождения, размеры и распространения поселений, найденных вдоль северной линии реки Балих. Кроме того, используя все технические и статистические данные, собранные из каждого населенного пункта, попытались выявить ареалы распределения поселений в регионе, для определения связей этих поселений между собой, изучить модели поселений, культурные структуры региона в каждом периоде, центров населенных пунктов и нижних городов, а также культуры региона и окружающих его культур и отношения между ними. В целом, принимая руины Харрана в качестве 


\section{Mehmet ÖNAL - Süheyla İrem MUTLU - Semih MUTLU}

центра, были оценены периоды и находки, найденные в поселениях находящиеся на севере, северо-западе, востоке от Великой мечети Харрана и ещё юго-запад, юговосток, восток и западные склоны Харрана Хёюка, а также поля вокруг внешней стены и возле неё, от центра к северу, северо-западу и северо-востоку.

Ключевые слова: руины Харрана, равнина Харран, исследование, схема поселения, культуры.

\section{Giriş}

Şanlıurfa'nın güneydoğusunda bulunan, doğudan Tek Tek Dağları, batıdan ise Fatik Dağları arasında uzanarak Suriye'yi geçip Cezire bölgesine doğru açılan, deniz seviyesi yüksekliği $400-550 \mathrm{~m}$ arasında değişen, yaklaşık olarak $40 \mathrm{~km}$ genişliğinde ve $55 \mathrm{~km}$ uzunluğunda bir alanı kapsayan Harran Ovası alüvyonlarla kaplı bir özellik gösterdiği için oldukça verimli bir ovadır. Ovanın bereketli yapısı sayesinde çok sayıda yerleşim yeri ortaya çıkmış ve pek çoğu her dönemde önemini korumuştur. Konumuyla ve bölgeler arası bağlantıların sağlandığı önemli kesişim yollarında bulunması sebebiyle çağlar boyunca önemli bir yerleşim alanı olarak tercih edilmiş olan Harran kenti ve Harran Ovası ve çevresi çok sayıda gezgin ve bilim insanı tarafindan ziyaret edilmiş ve aynı zamanda arkeolojik araştırmalar da gerçekleştirilmiştir (Yardımcı 2004; Önal vd. 2019: 469-479). Özellikle son dönemlerde hem ovada gerçekleştirilmiş olan Neolitik Dönem yüzey araştırmaları ve kazılar (Çelik 2015a: 315-317; Çelik 2015b: 81-83; Çelik 2016: 413-416; Çelik 2018: 55-57; Çelik 2019: 281-285; Çelik ve Bingöl 2016: 7-8; Güler ve Çelik 2015: 79-81) hem de ovanın doğusunda Tek Tek Dağları'nda yer alan Soğmatar ve yakın çevresindeki yüzey araştırmaları ve Soğmatar'da Nekropol Alanında yapılmış olan kazılar vasıtasıyla (Tek Tek Dağları'nda Tunç Çağlar, Demir Çağlar ve Roma Dönemi araştırmaları detayı için bknz: Albayrak ve Mutlu 2014: 337-339; Albayrak ve Mutlu 2015: 260-266; Albayrak ve Mutlu 2017: 526-535; Mutlu ve Albayrak 2018: 136-138; Albayrak 2019a: 652-661; Albayrak 2019b: 177-201; Albayrak 2019c: 271-274; Çelik ve Albayrak 2019: 62-63; Albayrak 2015: 238-241: Albayrak ve Çelik 2019: 256-258; Albayrak vd. 2019: 265-267; Albayrak 2020: 20-23; Albayrak ve Çelik 2020: 250-252) ova ve dağlik kesim arasında farklı dönemlerde kurulan kültürel ilişkilerin boyutu ve çevre bölgelerle bağlantının anlaşılabilmesi açısından oldukça büyük önem taşımaktadır (Ova ve tepelerde Neolitik Dönem ve öncesi tespit edilen yerleşimlerin detayları için bknz: Çelik ve Tosyagülü Çelik 2020a: 46-52; Çelik ve Tosyagülü Çelik 2020b: 305-306; Çelik ve Tosyagülü Çelik 2020c; Çelik 2007: 165-167; Çelik 2010: 258-263; Çelik 2011: 241-246; Çelik ve vd. 2011: 226-227; Çelik ve Bingöl 2016: 2-12).

Son derece önemli bir konumda yer alan ve çok fazla sayıda yerleşime ev sahipliği yapmış olduğu anlaşılan Harran Ovası'nda 2018 yılında başlattığımız ve 2020 yılında sürdürdügümüz yüzey araştırmalarımızda ${ }^{1}$ tüm teknik ve istatistiksel

\footnotetext{
1 Harran Üniversitesi öğretim üyesi Prof. Dr. Mehmet Önal başkanlığında, Bakanlık temsilcisi olarak Şanlıurfa Müzesi görevlilerinden Tuba ALPAY'ın denetiminde, Harran Üniversitesi Arkeoloji Bölümü öğretim elemanlarından Arş. Gör. Süheyla İrem Mutlu, Öğr. Gör. Semih Mutlu’nun katılımı ve Harran Üniversitesi Arkeoloji Bölümü mezunlarından Rahime SELIM, Jiyan ÇALIK, Ümmü Gülsüm GENTİR ve Orhan KAYAR, Harran
} 


\section{Harran Ovası Arkeolojik Yüzey Araştırması 2020 Yılı Çalışmalarının...}

verileri kullanarak bölgedeki yerleşimlerin yayılım alanları, bu yerleşimlerin birbirleriyle bağlantılarının saptanması, yerleşim şablonlarının çıkarılması, bölgenin her dönemde kültürel yapısının belirlenmesi, ticari güzergahlar, su yatakları, askeri ve ticari yollar, merkez ve merkeze bağl1 yerleşimler, aşağı şehirlerin tespitine yönelik çalışmalarla bölgeyle çevre kültürler arasındaki ilişkilerin belirlenmesi hedeflenmiştir.

Belirlemiş olduğumuz söz konusu hedefler doğrultusunda Şanlıurfa ili, Harran ilçesinden başlamak üzere Harran Ovası sınırları içerisinde kalan kırsal alanda gerçekleştirilen Harran Ovası Yüzey Araştırması 2020 çalışmalarımız ilk olarak Harran Ören Yeri merkez alınarak Harran Ulu Camii'nin kuzeyi, kuzeybatıs1, doğusu, Harran Höyük'ün güneybatı, güneydoğu ve güney, doğu ve batı yamaçları, ayrıca dış surun etrafı ve yakınındaki tarlalarda başlatılmıştır. Daha sonra araştırma alanı olarak Harran Ören Yeri merkez alınarak yakın çevresinden başlanıp doğu ve batı kısmı boyunca ilerlenerek Bozyazı Köyü, İmam Bakır Köyü, Tell Magrum, Seferköy, Balkat, Buğdaytepe, Dayanıklı, Doruç, Para Para, Sıralı Köyü Yakını (Çınar Tepe), Kırmıtlı, Sıralı, Eski Harran, Eski Harran Yakını Tepe, Güngören, Seksenören, Uluköy ve Tek Tek Dağları Yakınındaki alan olmak üzere köyler ve bu köylere bağlı mezralar teker teker gezilmiştir (Harita 1).

\section{2020 Yılında Araştırması Yapılan Alan ve Tespit Edilen Bulgular}

Harran Ovası Yüzey Araştırması 2020 çalışmalarımıza ilk etapta Harran Ören Yeri merkez alınarak Harran Ulu Camii’nin kuzeyi, kuzeybatısı, doğusu, Harran Höyük'ün güneybatı, güneydoğu, doğu ve batı yamaçları, ayrıca dış surun etrafi ve yakınındaki tarlalarda başlatılmıştır. Söz konusu gezilen alanlardan Harran Ulu Camii'nin kuzeyi, kuzeybatısı, doğusunda yüzeyde yoğun olarak Orta Çağ İslami Dönem'e ait süslemeli taş bloklardan oluşan mimari elemanlar ve yine aynı döneme ait çanak çömlek ve diğer buluntular tespit edilmiştir. Harran Höyük'ün güney ve güneydoğu yamacı boyunca devam ettirilen çalışmalar neticesinde ise höyük sınırlarına yakın alanlarda az miktarda Orta Çağ İslami Dönem olmak üzere yoğunluklu olarak Demir Çăğ dan Tunç ve Kalkolitik Dönemlere ait çanak çömlek parçaları ele geçmiştir. Harran Dış Sur çevresinde yapılan araştırmalarda burasının Orta Çağ'da mezarlık olarak kullanıldığı anlaşılmıştır. Yüzeyde toplanan kireçtaşından mezar taşı parçaları da bunu destekler niteliktedir. Gezilen alanda ayrıca çoğunluğu İslami Dönem olmak üzere Demir Çağ ve Tunç Çağ seramiklerine de benzeyen çanak çömlek parçaları toplanmıştır. (Resim 2)

\section{1-Harran Ören Yeri Kuzeyi, Kuzeybatısı ve Kuzeydoğusu Yerleşimler (Resim 3-8)}

Üniversitesi Arkeoloji Bölümü öğrencilerinden Türkan Sultan BİLGİN ve Ezgi ÖRENLER'in yardımlarıyla çalışmalarımız yürütülmüştür. 


\section{Mehmet ÖNAL - Süheyla İrem MUTLU - Semih MUTLU}

Harran Ovası 2020 yılı Yüzey Araştırması kapsamında Harran Ören Yeri merkez alınarak araştırılan alan içerisinde kuzeybatıda en uzak 12,2 km'de bulunan Para Para Höyük'e (46,8 ha), kuzeydoğuda Seksen Ören Höyük'e (71,4 ha) ve doğuda 4,68 km'de bulunan Bozyazı Höyük'e kadar gezilmiştir.

Gezilmiş olan bu höyüklerde yayılım alanı 5 hektara kadar ulaşan yerleşimler küçükten büyüğe sırasıyla; Çınar Tepe (0,35 ha), İmam Bakır (2,66 ha), Dayanıklı Tepe (4,11 ha), Ağc1l Höyük (5,41 ha) ve Kırmıtlı (5,49 ha) yerleşimleridir. Nispeten az yayılım alanına sahip olan bu yerleşimlerde ortak özellik olarak çok fazla sayıda çanak çömlek verileri ele geçmemiş olsa da saptanan dönemin yoğunluklu olarak Orta Çağ-İslami Dönem'e ait olduğu anlaşılmaktadır. Ayrıca yoğunluk olarak çok az miktarda değerlendirebilecek Neolitik Dönem, Erken Tunç Çağı, Orta-Geç Tunç Çağı, Demir Çağ ve Roma Dönemi’ne ait çanak çömlek parçalarına rastlanılmıştır. Söz konusu yerleşimlerden İmam Bakır Höyük hariç geri kalanı Harran Ören Yeri'nin kuzeyinde yer almaktadırlar ve muhtemelen bu yerleşimlerin özellikle İslami Dönem'de Harran Kenti'ne bağlı küçük yerleşimler olduğu tahmin edilmektedir.

Harran Ören Yeri'nin kuzeyinde yer alan ve yayılım alanı 6 ile 10 hektar arasında değişen yerleşimler ise küçükten büyüğe sırasıyla; Doruç Tepe (8,93 ha) ve Güngören Höyük (9,38 ha) olarak belirlenmiştir. Bu höyüklerin ikisinin her ne kadar yayılım alanları biraz daha geniş olsa da yoğun tahribattan dolayı çanak çömlek verileri çok sınırlı olarak ele geçmiştir. Ancak bu olumsuz duruma rağmen genel bir değerlendirme yapılacak olursa az miktarda İslami Dönem ve Roma Dönemi olmak üzere nispeten yoğunluğun Erken ve Orta Tunç Çağlar'da olduğu anlaşılmaktadır.

Harran'ın kuzey ve kuzeybatısı boyunca gezilen alan içerisinde 10 ile 16 hektar arasında yayılım gösterdiği anlaşılan höyükler sırasıyla; Uluköy Höyük (11,94 ha), Buğday Tepe (15 ha), Siralı Höyük (15,2 ha) (Resim 6) ve Kazıkl1-Hazuk Höyük (16 ha) olarak saptanmıştır. Ovanın geniş yayılım gösteren höyükleri içerisinde değerlendirilebilecek bu höyüklerde ise yoğunluğun özellikle Erken Tunç Çă̆’ın III ve IV evresine ait olduğu gözlenmekle birlikte ayrıca Geç Kalkolitik Dönem, kısmen Halaf-Ubaid boyalıları, Orta ve Geç Tunç Çağ, nispeten daha az miktarda Demir Çağ ve sadece höyük konisinin tepe kısımlarında da İslami Dönem'e ait çanak çömlek buluntularına rastlanılmıştır. Ayrıca yayılım alanı genişliğine bakıldığında yayılımın en geniş sınırını da Erken Tunç Çağ başta olmak üzere genel olarak Tunç Çağların oluşturduğu gözlenmiştir.

Harran Ören Yeri'nin kuzeybatı ve kuzeydoğusunda 40 hektar üzerinde yayılım alanına sahip olan ve ovanın oldukça geniş yayılım gösteren höyüklerine bakıldığında sırasıyla Eski Harran Höyük (45,63 ha)(Resim 7), Para Para Höyük (46,8 ha) (Resim 5) ve Seksenören Höyük (71,4 ha) (Resim 8) gelmektedir. Bu höyükler içerisinde Eski Harran Höyük'te yoğun yapılaşma ve tahribattan dolayı yayılım alanının saptanmasında oldukça zorlanılmış olsa da höyügün oldukça önemli ve geniş yayılım gösteren bir Halaf-Ubaid merkezi olduğu anlaşılmıştır. Ayrıca Erken ve Orta Tunç Çağlar olmak üzere az miktarda Roma ve İslami Dönemlere ait 


\section{Harran Ovası Arkeolojik Yüzey Araştırması 2020 Yılı Çalışmalarının...}

çanak çömlek verileri burasının hemen her dönemde yerleşim yeri olarak tercih edildiğini göstermektedir.

Ovada hem yüksekliğiyle hem de oldukça geniş yayılım alanıyla dikkat çeken Para Para Höyük ve Seksenören Höyük'ün ise özellikle MÖ 3. Binyılın ikinci yarısından MÖ 2. Binyılın ortalarına kadar önemli birer Tunç Çağı kent merkezi niteliğine sahip oldukları düşünülmektedir. Nitekim özellikle her cepheden ve yamaçlardan ele geçen yoğun Erken Tunç Çağı III-IV ve Orta Tunç Çağı çanak çömlek ve diğer küçük buluntular bu höyüklerin söz konusu dönemlerde oldukça geniş yayılım gösteren büyük kentler olduklarını destekler niteliktedir. Ayrıca bu höyüklerin her dönemde Harran Kenti'ne bağlı önemli merkezler oldukları da özellikle dikkat çekmektedir.

Son olarak Harran'ın 13,21 km doğusunda tepe kotu $427 \mathrm{~m}$ olan ve 745 hektarlık bir alanda Çağbaşı Yaygılı arasından Tek Tek Dağları'nın batı sınırına kadar olan tarla alanlarında gerçekleştiği düşünülen Carrhae Savaşının izlerinin saptanmasına yönelik alan taraması gerçekleştirilmiştir. Yüzeyde yirmiye yakın çakmaktaşı alet ve alet olmayan parçalar tespit edilerek toplanmış olsa da söz konusu alan içerisinde savaşın izlerini gösteren metalden yapılmış savaş aletlerine henüz rastlanılamamıştır; ancak yazılı kaynaklarda geçen savaş alanının tespitine yönelik çalışmalarımızı önümüzdeki dönemlerde de devam ettirmeyi planlamaktayız.

\section{DEĞERLENDİRME}

Harran Ören Yeri'nin doğusu, batıs1, güneyi, kuzeybatı ve kuzeydoğu hatlarında öncelikli olarak Harran merkeze en yakın alandan başlanılarak sürdürdügümüz araştırmalarda Harran Kenti ile bağlantılı küçüklü büyüklü yerleşimlerin tespiti, çevre yerleşimlerle kurulan kültürel ilişkinin boyutları, yerleşimlerden ele geçen arkeolojik materyaller değerlendirilerek anlaşılmaya çalışılmıştır. Ovada 2018 yılı içerisinde gerçekleştirdiğimiz çalışmalarda da Eski çağlardan itibaren önemli bir konumda olan Balih Nehri'ne bağlanan Selgelen Deresinin güney hattı boyunca sıralanan yerleşimlerde araştırmalarda bulunulmuştu. Harran Ören Yeri'nin güneyi, batı ve kuzeybatısında yerleşimlerin boyut, dönem ve ele geçen çanak çömlek verilerine göre bir değerlendirme yapıldığında ilk olarak, Balkat Höyük (Resim 4), Yukarı Yarımca Höyük ve Tel Magrum (Resim 3) gibi 10 hektardan büyük yayılım alanına sahip yerleşimlerin büyük, ana merkezler olarak kesintisiz her dönemde yerleşim gördüğü anlaşılmıştır. Bu sezon gerçekleştirilen araştırmalarımız neticesinde ise, merkezi yerleşim şablonu temel alındığında, Harran Kenti'nin 15 km kuzey ve kuzeybatısı sinırlarına kadar ilerlendiğinde Para Para Höyük ve Seksenören Höyük'ün Harran Kenti'ne bağlı en büyük ana merkezler oldukları ve söz konusu bu büyük ana yerleşimlerin etrafında da onlara bağlı irili ufaklı uydu yerleşimlerin varlığ 1 dikkat çekmektedir. Bu durum Harran Kenti'nin ve kentin kurduğu sosyo-ekonomik ve kültürel ilişkilerini gösteren etki alanının yaklaşık olarak 15 km kuzey ve kuzeybatıya doğru genişlediğini gösterir niteliktedir.

Söz konusu yerleşimlerde çanak çömlek verilerine dayanarak özellikle dönem olarak M.Ö. 3. Binyılın ikinci yarısına tarihlendirilen Erken Tunç Çağı III-IV 
evrelerinin varlığı yoğun olarak tespit edilmiştir. Daha küçük boyutta ve yayılım alanı nispeten daha dar olan yerleşimler ise, merkezi kentlere bağlı ve onların etrafinda biraz daha küçük boyutta konumlanan, 5 hektardan büyük yayılım alanına sahip, daha küçük yerleşimler arasında yer almaktadır. Bu yerleşimler dışında kalan diğer yerleşimlerin ise 5 hektardan küçük yayılım alanına sahip oldukları ve özellikle 2 hektardan küçük yayılım alanına sahip olanlarda çoğunlukla yoğun olarak Halaf ve bir kısmında da Ubaid dönemlerine ait çanak çömleklerin varlığı özellikle dikkat çekmektedir ve söz konusu bu yerleşimlerin daha çok düz yerleşimler oldukları ve Neolitik-Kalkolitik Çağ veya Neolitik-İslami Dönem olmak üzere en fazla iki farklı dönemde yerleşim gördükleri ve daha geç dönemlerdeki büyük kentlerden ziyade küçük köy veya kısa süreli geçici yerleşimler olarak kullanım gördükleri düşünülmektedir.

İki sezon gerçekleştirilen yüzey araştırmamız kapsamında gezilen yerlerden elde edilen ilk değerlendirmelere göre çanak çömlek ve diğer buluntu yoğunluğu dikkate alınarak sırasıyla İslami Dönem (33 adet yerleşimde), Erken Tunç Çağı (24 adet yerleşimde), Demir Çağ (19 adet yerleşimde), Erken ve Orta Kalkolitik (HalafUbaid) dönemleri (18 adet yerleşimde) Orta Tunç ve Geç Tunç Çağlarının (17 adet yerleşimde) varlıkları saptanmıştır (Resim 2). Özellikle geniş hektara sahip, büyük yerleşimlerde gerçekleştirilen yoğun taramalardan elde edilen verilere göre ise en geniş yayılıma sahip dönemin Erken Tunç Çağı'na ait olduğu gözlenmiştir. Önümüzdeki sezonlarda gerçekleştirilmesi planlanan araştırmalarımızla, gezilen yerlerin sayıları arttıkça daha detaylı ve geniş kapsamlı sonuçlar ortaya konulabilecek ve tespit ettiğimiz yerleşimler arasında her dönemde kurulan ilişkiler saptanıp ovadaki yerleşim şablonu çıkarılabilecek, yerleşimlerin birbirleriyle bağlantıları ve kültürel gelişimi daha iyi değerlendirilebilecektir.

\section{KAYNAKÇA}

ALBAYRAK, Y. ve S. İ. MUTLU 2014. "Soğmatar Kutsal Alanı ve Yakın Çevresi Yüzey Araştırması, 2012", Araştırma Sonuçları Toplantısı 31/2: 337-352.

ALBAYRAK, Y. 2015. "Soğmatar Kült Merkezi İle İlgili Yeni Öneriler”, Belgü, Ardahan Üniversitesi Insani Bilimler ve Edebiyat Fakültesi Dergisi 2: 237252.

ALBAYRAK, Y. ve S. İ. MUTLU 2015. "Soğmatar Kutsal Alanı ve Yakın Çevresi Yüzey Araştırmas1, 2013”, Araştırma Sonuçları Toplantısı 32/2: 259-278.

ALBAYRAK, Y. ve S. İ. Mutlu 2018. "Soğmatar Nekropolü 2016 Y1lı Temizlik Çalışmaları", Kazı Sonuçları Toplantısı 39/3: 525-544.

ALBAYRAK, Y. 2019a. "Soğmatar Nekropolü 2017 Yılı Temizlik Çalışmaları”, Kazı SonuçlarıToplantısı 40/3: 651-668.

ALBAYRAK, Y. 2019b. Göbekli Tepe'den Edessa'ya Şanlıurfa. Arkeoloji ve Sanat Yayınları, İstanbul.

ALBAYRAK, Y. 2019c. "Soğmatar”, M. Önal, S. İ. Mutlu ve S. Mutlu (yay.) Harran ve Çevresi Arkeoloji: 271-284. Şurkav Yayınları, Şanlıurfa. 
ALBAYRAK, Y., S. İ. MUTLU, S. MUTLU ve B. ÇELİK 2019. "Soğmatar'da Sunaklı Kaya Oyuğu Mezarlar", Karadeniz Uluslararası Bilimsel Dergi 41: 263-274.

ALBAYRAK, Y. 2020. "Soğmatar Nekropolü Roma Donemi Kaya Mezarları", K.

S. Girginer (yay.) Amanosların Gölgesinde Hayriye Akıl Anı Kitabı: 19-28. Ege Yayınları, İstanbul.

ALBAYRAK, Y. ve B. ÇELIKK 2019. "Soğmatar Çevresi Kaya Mezarları", Karadeniz Uluslararası Bilimsel Dergi 43: 255-261.

ALBAYRAK, Y. ve B. ÇELİK 2020. "Soğmatar Rölyef ve Yazıtları”, Karadeniz Uluslararası Bilimsel Dergi 48: 246-260.

ÇELIK, B. 2007. "Şanlıurfa Yeni Mahalle - Balıklıg̈̈l Höyügü̆”, in: M. Özdoğan/N. Başgelen (eds.), Anadolu'da Uygarliğın Doğuşu ve Avrupa'ya Yayılımı, Türkiye'de Neolitik Dönem, Yeni Kazılar, Yeni Bulgular (İstanbul 2007), 165-178.

ÇELIK, B. 2010. "Hamzan Tepe in the Light of New Finds", Documenta praehistorica XXXVII, 2010, 257-268.

ÇELIK, B. 2011. "Karahan Tepe a new cultural centre in the Urfa area in Turkey". Documenta Praehistorica XXXVIII (2011), s.241-253.

ÇELIK, B. 2015a. "Şanlıurfa İli Merkez İlçesi Neolitik Dönem ve Öncesi Yüzey Araştırmas1, 2013", Araştırma Sonuçları Toplantısı 32/2: 311-328.

ÇELIK, B. 2015b. "Şanlıurfa İli Yüzey Araştırması", Belgü, Ardahan Üniversitesi Insani Bilimler ve Edebiyat Fakültesi Dergisi II: 79-99.

ÇELIK, B. 2016. "Şanlıurfa İli Merkez İlçesi Neolitik Dönem ve Öncesi Yüzey Araştırmas1, 2014”, Araştırma Sonuçları Toplantısı 33/2: 409-426.

ÇELIK, B. 2018. "Şanlıurfa İli Neolitik Dönem Yüzey Araştırması, 2018", Karadeniz Uluslararası Bilimsel Dergi 40: 52-63.

ÇELIK, B. 2019. "2017 Yılı Şanlıurfa İli Merkez İlçesi Neolitik Çă̆ ve Öncesi Yüzey Araştırması”, Araştırma Sonuçları Toplantısı 36/1: 275-296.

ÇELIK, B. ve Y. ALBAYRAK 2019. "Soğmatar'dan Ele Geçen Bir Kartal Figürü", Karadeniz Uluslararası Bilimsel Dergi 42: 60-67.

ÇELIK, B., M. GÜLER, G. GÜLER 2011. “Türkiye'nin Güneydoğusunda Yeni Bir Çanak Çömleksiz Neolitik Yerleşim: Taşlı Tepe / A New Pre-Pottery Neolithic Settlement in Southeastern Turkey: Taşlı Tepe", Anadolu / Anatolia 37, 2011, 225-236.

ÇELIK, B. ve A. BINGÖL 2016. "Şanlıurfa Province Central District Tektek Mountains Year 2015 Surface Survey", Kafkas Üniversitesi Sosyal Bilimler Dergisi, Ek 1: 1-20.

ÇELIK ve TOSYAGÜLÜ ÇELIK 2020a. "Harbetsuvan Tepesi 2018 Y1l Kazı Çalışması", Karadeniz Uluslararası Bilimsel Dergi 47: 44-58.

ÇELIK ve TOSYAGÜLÜ ÇELIK 2020b. "Harbetsuvan Tepesi 2019 Y1l Kazı Çalışması”, Karadeniz Uluslararası Bilimsel Dergi 48: 303-326. 
ÇELIKK ve TOSYAGÜLÜ ÇELIK 2020c. "Şanlıurfa Tek Tek Dağları Coğrafyasında Neolitik Dönemden Roma Dönemine Taş Ocakları ve Kaya Mezarları", Kafkas Üniversitesi Sosyal Bilimler Enstitüsü Dergisi 26: 399-416.

GÜLER, M. ve B. ÇELIKK 2015. "Şanlıurfa Bölgesi Neolitik Dönem Araştırmaları", Belgü, Ardahan Üniversitesi İnsani Bilimler ve Edebiyat Fakültesi Dergisi 1: 75-102.

MUTLU, S. İ. ve Y. ALBAYRAK 2018. "Harran ve Soğmatar'da Sin Kültünün Varlığı", Karadeniz Uluslararası Bilimsel Dergi, sayı 37: 133-144.

ÖNAL, M., S. İ. MUTLU, S. MUTLU 2019. "Harran Ovası Yüzey Araştırmas1 2018", Araştırma Sonuçları Toplantısı 37/2: 469-486.

YARDIMCI, N. 2004. Harran Ovası Yüzey Araştırması I-II, Archaeological Survey in the Harran Plain. (Eds.) Ayşe H. Özkan \& J.D. Carpenter Efe, Print A Grafik ve Matbaacilik, İstanbul. 


\section{Harran Ovası Arkeolojik Yüzey Araştırması 2020 Yılı Çalışmalarının...}

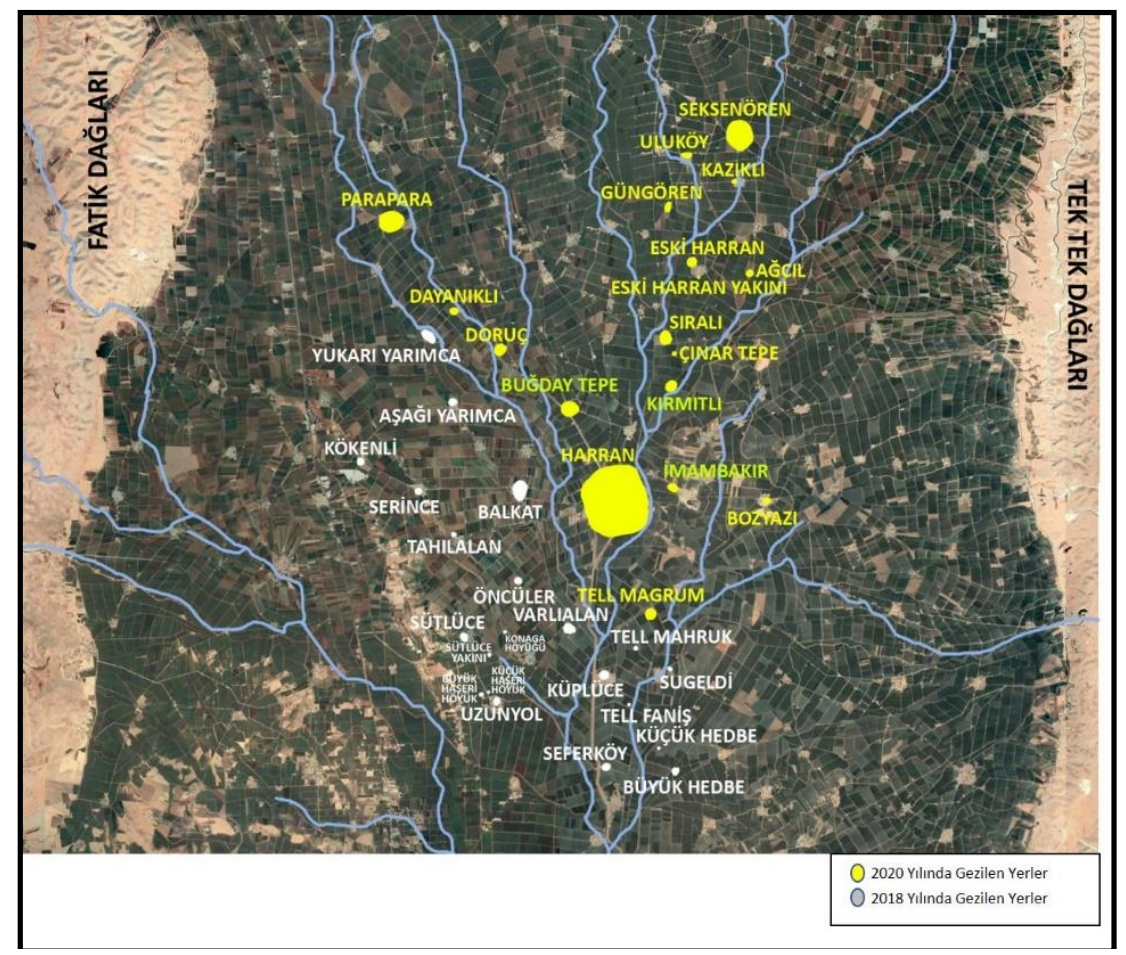

Yerleşimler

Harita 1: Harran Ovası 2018 ve 2020 Y1llarında Tespit Edilen

2018 ve 2020 Yılları Yerleşim-Alan Grafiği
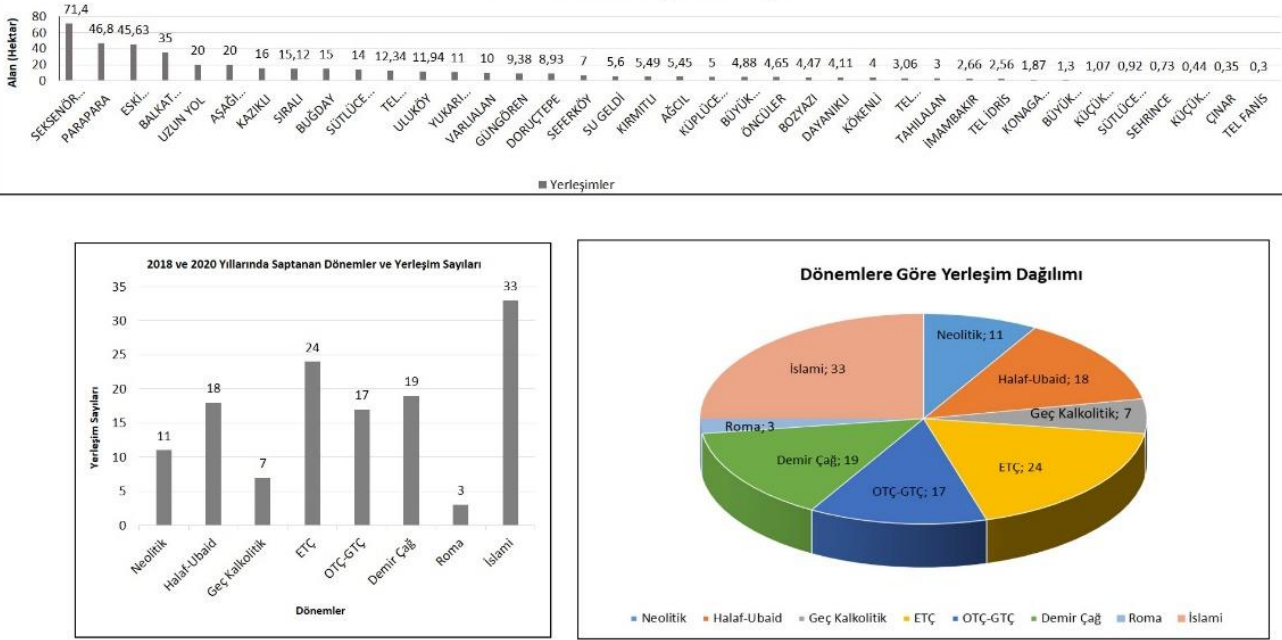

Resim 1: Harran Ovası 2018-2020 Yılları Yerleşim-Alan Grafiği ve Yerleşim Dağılımı Grafiği 


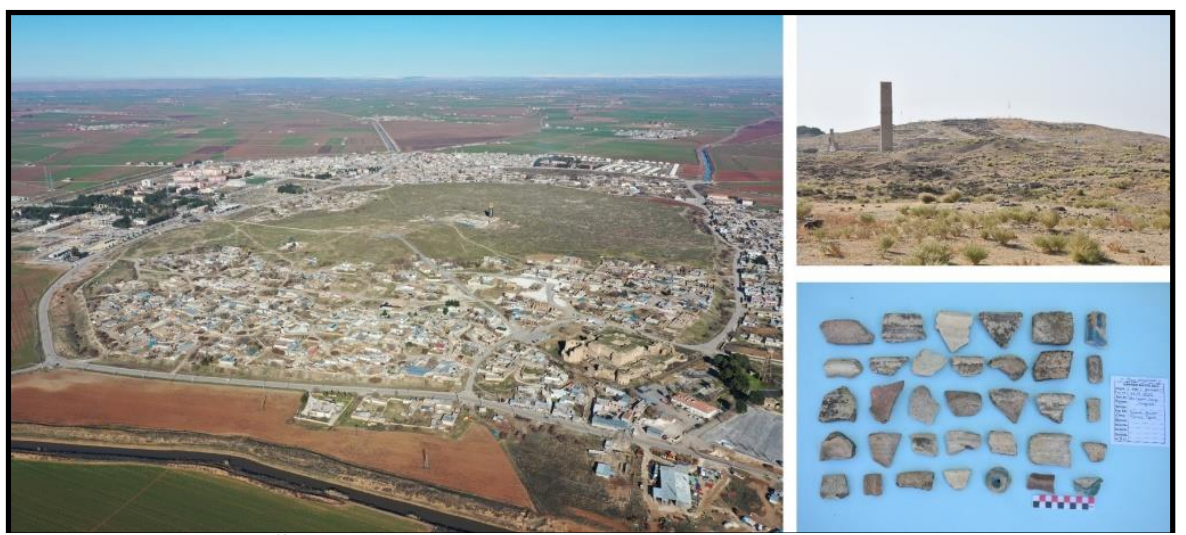

Resim 2: Harran Ören Yeri ve Harran Höyük Genel Görünüm ve Buluntular

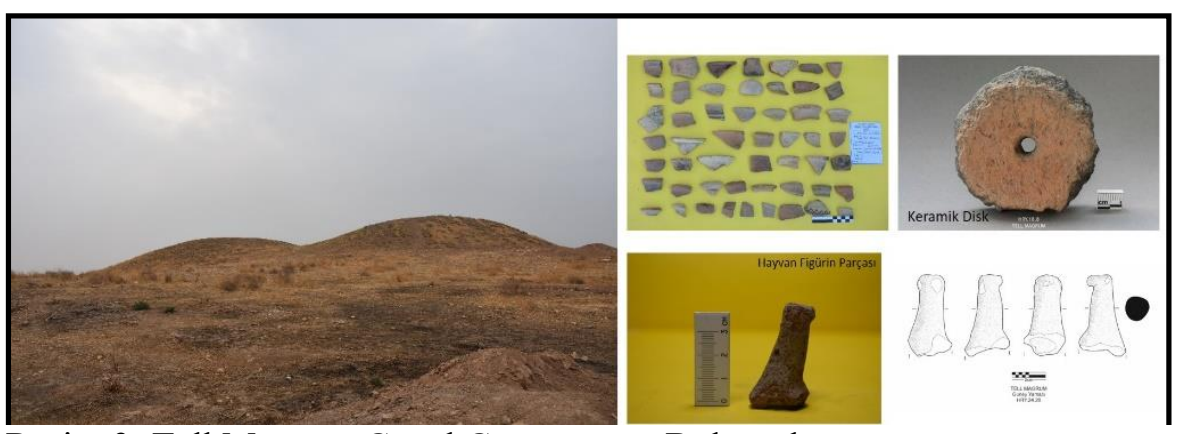

Resim 3: Tell Magrum Genel Görünüm ve Buluntular

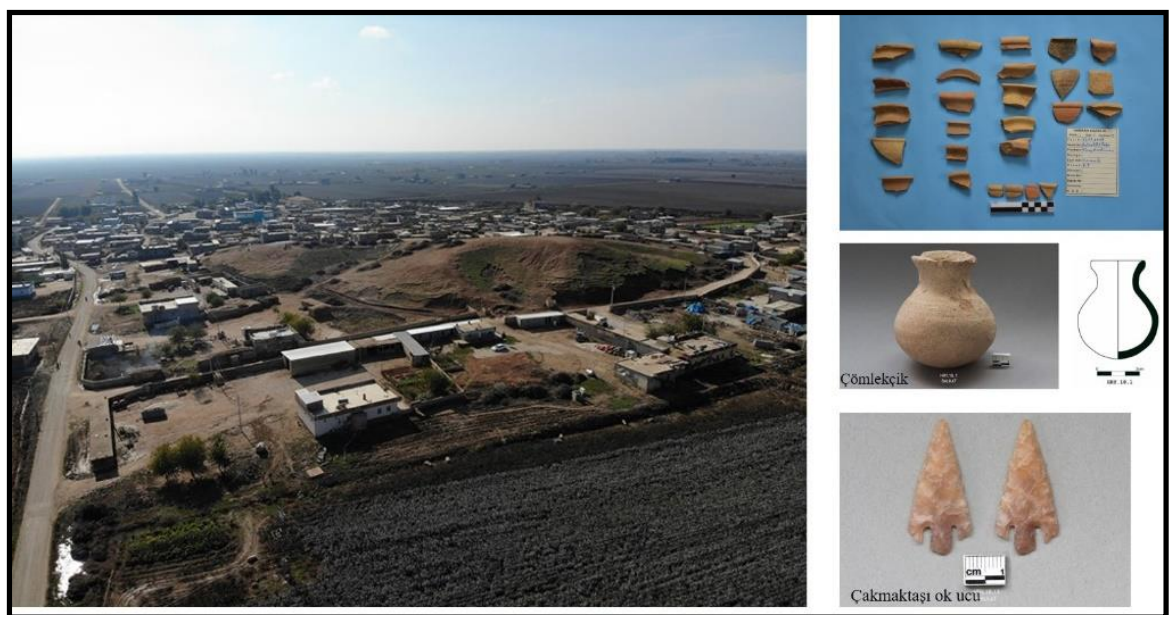

Resim 4: Balkat Höyük Genel Görünüm ve Buluntular 
Harran Ovası Arkeolojik Yüzey Araştırması 2020 Yılı Çalışmalarının...

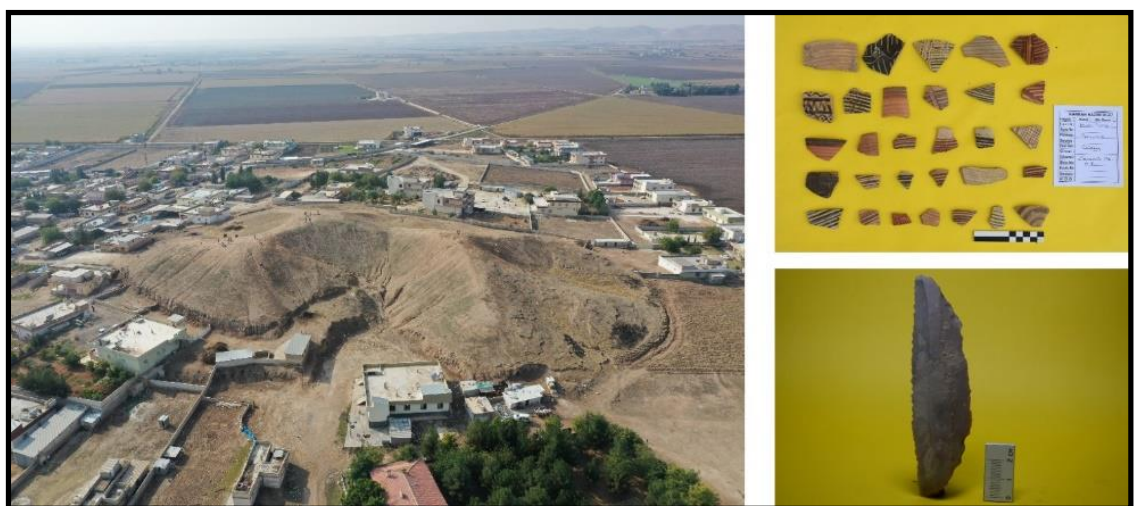

Resim 5: Para Para Höyük Genel Görünüm, Çanak Çömlek ve Çakmaktaşı Alet
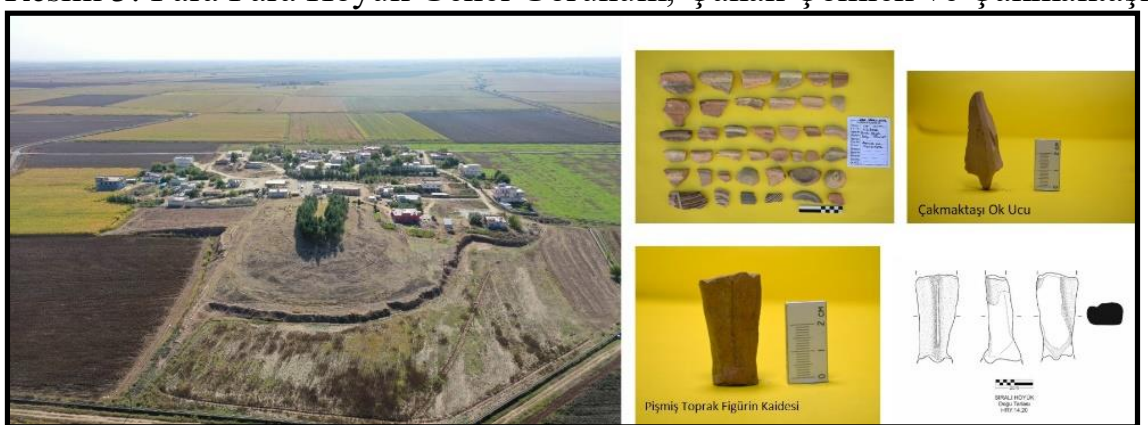

Resim 6: Sıralı Höyük Genel Görünüm, Çanak Çömlek ve Diğer Buluntular

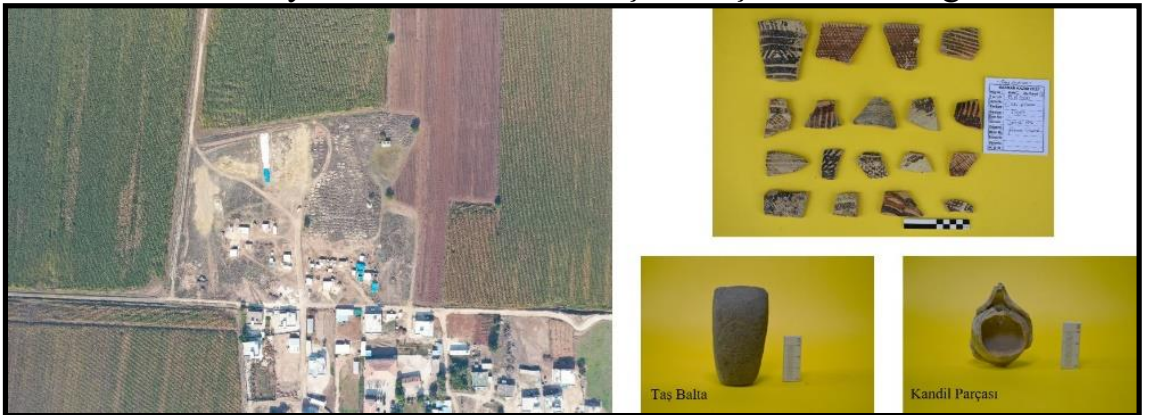

Resim 7: Eski Harran Genel Görünüm, Çanak Çömlek ve Diğer Buluntular

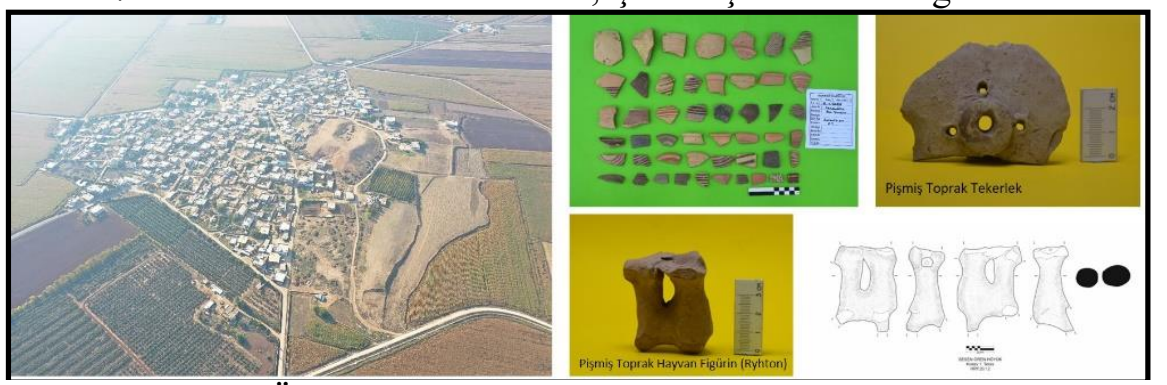

Resim 8: Seksen Ören Höyük Genel Görünüm ve Diğer Buluntular 